\title{
The Hyperactivity of Efferent Auditory System in Patients with Schizophrenia: A Transient Evoked Otoacoustic Emissions Study
}

\author{
Noor Alaudin Abdul Wahab ${ }^{1,4} \bowtie$, Suzaily Wahab², Abdul Hamid Abdul Rahman², \\ Dinsuhaimi Sidek ${ }^{3}$, and Mohd. Normani Zakaria ${ }^{1}$ \\ ${ }^{1}$ Audiology Programme, School of Health Sciences, Universiti Sains Malaysia, Kelantan, Malaysia \\ 2Department of Psychiatry, Faculty of Medicine, Universiti Kebangsaan Malaysia Medical Center, Wilayah Persekutuan, Malaysia \\ ${ }^{3}$ Department of Otorhinolaryngology, School of Medicine, Universiti Sains Malaysia, Kelantan, Malaysia \\ ${ }^{4}$ Audiology Programme, School of Rehabilitation Sciences, Faculty of Health Sciences, Universiti Kebangsaan Malaysia, Wilayah Persekutuan, \\ Malaysia
}

Objective Electrophysiological studies, which are mostly focused on afferent pathway, have proven that auditory processing deficits exist in patients with schizophrenia. Nevertheless, reports on the suppressive effect of efferent auditory pathway on cochlear outer hair cells among schizophrenia patients are limited. The present, case-control, study examined the contralateral suppression of transient evoked otoacoustic emissions (TEOAEs) in patients with schizophrenia.

Methods Participants were twenty-three healthy controls and sixteen schizophrenia patients with normal hearing, middle ear and cochlear outer hair cells function. Absolute non-linear and linear TEOAEs were measured in both ears by delivering clicks stimuli at $80 \mathrm{~dB}$ SPL and $60 \mathrm{~dB}$ SPL respectively. Subsequently, contralateral suppression was determined by subtracting the absolute TEOAEs response obtained at $60 \mathrm{dBpe}$ SPL during the absence and presence of contralateral white noise delivered at $65 \mathrm{~dB}$ HL. No attention tasks were conducted during measurements.

Results We found no significant difference in absolute TEOAEs responses at $80 \mathrm{~dB}$ SPL, in either diagnosis or ear groups ( $\mathrm{p}>0.05$ ). However, the overall contralateral suppression was significantly larger in schizophrenia patients $(\mathrm{p}<0.05)$. Specifically, patients with schizophrenia demonstrated significantly increased right ear contralateral suppression compared to healthy control $(\mathrm{p}<0.05)$.

Conclusion The present findings suggest increased inhibitory effect of efferent auditory pathway especially on the right cochlear outer hair cells. Further studies to investigate increased suppressive effects are crucial to expand the current understanding of auditory hallucination mechanisms in schizophrenia patients.

Psychiatry Investig 2016;13(1):82-88

Key Words Schizophrenia, Efferent pathways, Otoacoustic emissions, Hair cells.

\section{INTRODUCTION}

Schizophrenia, a psychiatric illness with reported point prevalence of $4.6 / 1000,{ }^{1}$ is a brain disorder. ${ }^{2-4}$ Rish et al., ${ }^{5}$ in addition, reported that the illness was indeed a network disease of

\footnotetext{
Received: March 11, 2015 Revised: May 18, 2015

Accepted: May 30, 2015 Available online: October 14, 2015

$\triangle$ Correspondence: Noor Alaudin Abdul Wahab, MSc

Audiology Program, School of Rehabilitation Sciences, Faculty of Health Sciences, Universiti Kebangsaan Malaysia, Jalan Raja Muda Abdul Aziz, Kuala Lumpur 50300, Malaysia

Tel: +6039289 5018, Fax: +60326986039

E-mail: noor.alaudin@ukm.edu.my

(a) This is an Open Access article distributed under the terms of the Creative Commons Attribution Non-Commercial License (http://creativecommons.org/licenses/by$\mathrm{nc} / 3.0$ ) which permits unrestricted non-commercial use, distribution, and reproduction in any medium, provided the original work is properly cited.
}

disrupted interaction among various brain regions. As human brain regulates various systems of human body, its dysfunction could lead to multiple symptoms found in schizophrenia. These include but not limited to auditory hallucinations and deficiency in speech and language processing. Since auditory hallucinations, speech and language are related to hearing, it is reasonably acceptable that auditory related functions were affected in patients with schizophrenia. Moreover, as auditory hallucinations are common symptoms in schizophrenia, investigating auditory processing system in the affected patients is important. Perhaps this could, in general, clarify our understanding on the mechanism of schizophrenia.

Reports on auditory processing deficits in patients with schizophrenia have been widely documented. ${ }^{6-9}$ As previously 
mentioned, speech-auditory processing deficits are associated with the psychiatric illness. Hence, due to the dominant functions of left brain on speech-auditory processing, speculating left brain abnormalities in patients with schizophrenia is logical. The presence of verbal auditory hallucination (VAH); i.e., hearing voices without their external presence; strengthens the assumption. Interestingly, the speculation is supported by abnormal findings on neuroimaging studies related to the left lobe functional ${ }^{10-13}$ and anatomical structures. ${ }^{14-17}$ In addition, abnormal findings in patients with schizophrenia during dichotic listening test also suggest left temporal lobe abnormality. An active competition, within the lobe, between auditory hallucination and externally delivered sounds led to reduction in their right ear advantage..$^{18}$ Nevertheless, these findings focused on the higher auditory center. As auditory processing also involves subcortical regions, the investigation should include these regions as well.

Findings on auditory processing deficits involving subcortical regions have added valuable information in schizophrenia. For instance, increased lateral asymmetry, ${ }^{19}$ anomalies in auditory brainstem response $(\mathrm{ABR})^{20,21}$ and middle latency response $(\mathrm{MLR})^{22}$ have been documented. These abnormalities strengthen the idea of auditory processing deficits in the population. However, these studies observed the bottom-up processing of auditory stimuli. In other words, the objectives focused on the ability of afferent auditory pathway to process the incoming auditory signals. In reality, our auditory system is not simply a "one-way traffic" that carries auditory stimuli from bottom to higher auditory centers, particularly the auditory cortex. The fact is efferent or "top-down" auditory pathways do exist in humans. ${ }^{23,24}$ These pathways play significant roles in regulating peripheral auditory system, including the outer hair cells of the cochlear. ${ }^{24-26}$ Together with afferent pathway, they form multiple feedback loops to modulate the function of auditory system. ${ }^{27}$ Hence, investigation on efferent pathway should receive equal priority.

The complex structures and physiological functions of humans' efferent auditory pathway have not been thoroughly explored. The current beliefs are, at this point, the pathway alters the micro mechanics of cochlear outer hair cells (OHCs). The beliefs are supported anatomically with the presence of medial olivocochlear (MOC) and cortico-olivocochlear bundles which are found at brainstem and higher auditory centers respectively. ${ }^{19}$ The MOC projects its myelinated fibers from the medial superior olivary complex (SOC) before it terminates at the base of contralateral cochlear OHCs. ${ }^{23-25}$ Similarly, the existence of cortico-olivocochlear pathway in humans was also reported, which enables the modulation of cochlear micro-mechanisms via auditory cortex. ${ }^{18,19}$ For instance, selective auditory attention which activates primary and secondary au- ditory cortex has been postulated to affect OHCs mechanisms. ${ }^{21,26}$ Interestingly, the amplitude of otoacoustic emissions (OAE) was reduced if auditory cortices were electrically stimulated. ${ }^{24}$ In addition, together with afferent system, the corticofugal system helps in modulating multiple feedback loops of auditory system. ${ }^{27,28}$ Hence, by exploring the function of efferent pathway could assist us in explaining the mechanisms of auditory processing in patients with schizophrenia.

The investigation on the medial olivocochlear (MOC) pathway in patients with schizophrenia was pioneered by Veulleit et al. ${ }^{29}$ Since then, limited reports have been published on the efferent auditory pathway of the clinical population. They reported that patients with schizophrenia showed absence of contralateral suppression asymmetry which reflects the absence of the right ear advantage (REA). In contrast, normal healthy controls showed higher contralateral suppression on the right ear. They concluded that the absence of lateral asymmetry in schizophrenia patients MOC system may lead to central lateralization anomalies.

The contralateral suppression of transient evoked otoacoustic emissions (TEOAE) is a clinical procedure to quantify the magnitude of OHCs suppression. ${ }^{30}$ It permits an indirect, noninvasive, evaluation of MOC (efferent) functions. The procedure requires the amplitude of TEOAEs to be recorded separately in the absence and presence of contralateral noise. ${ }^{31-33}$ In an intact auditory pathway, the presence of contralateral noise reduces the amplitude of TEOAE in the ear which it is being recorded. The contralateral suppression was defined as a positive difference in TEAOE amplitude between quiet and noise. ${ }^{34,35}$ An intact efferent pathway should contribute to at least $1 \mathrm{~dB}$ SPL of contralateral suppression. ${ }^{36}$ Hence, by using contralateral suppression, we are indirectly assessing the intactness of efferent auditory fibers.

The current, case-control, study aims to investigate the efferent auditory pathway of patients with schizophrenia, by using a non-invasive contralateral suppression of linear TEOAE. The main research question is whether deficits in efferent auditory pathway exist in patients with schizophrenia. This is important due to empirical evidences that support the existence of auditory processing deficits in the group. As a matter of fact, the afferent and efferent auditory pathways form a multi-level auditory feedback loops in human's auditory system. The existence of the loop systems further complicates our understanding in auditory processing deficits among patients with schizophrenia. As in the afferent fibers, contributions from efferent pathway in schizophrenia are yet to be explored. Perhaps, the investigation of efferent auditory pathway would update the current knowledge and understanding on auditory processing among schizophrenia patients. 


\section{METHODS}

\section{Participants}

The current case-control study involved a total of 39 randomly selected right handed subjects who written consent was obtained prior to audiological assessments. Ethical approval was obtained from Universiti Kebangsaan Malaysia Medical Centre (UKMMC) ethics committee. Subjects, in order to be included, must have normal hearing, clinically stable with Brief Psychotic Rating Scales (BPRS) less than $31^{37}$ and able to cooperate for assessments. On the other hand, subjects with extrapyramidal symptoms, neurological disorders and severe psychotic conditions were excluded. Out of the total subjects, 16 (10 males; 6 females) were schizophrenia patients aged between 19-44 years old (mean: 32.51, $\mathrm{SD}=6.93$ ) recruited from psychiatry clinic Universiti Kebangsaan Malaysia Medical Centre (UKMMC). The diagnosis of schizophrenia was confirmed following the DSM-IV, while the validated Malay version of Psychotic Symptom Rating Scales (MyPSYRATS) was used to determine the severity of psychosis. The MyPSYRATS had shown good internal consistency $(\mathrm{r}=0.85)$ and interrater agreement $(\mathrm{ICC}=0.877,95 \% \mathrm{CI}=0.336-0.941) .{ }^{38}$ At the time of assessment, all patients were currently on the second generation antipsychotics. 23 healthy subjects aged between $22-36$ years old (mean $=27.48, \mathrm{SD}=3.98$ ) were chosen as controls (10 males; 13 females).

\section{Audiological procedures}

All subjects underwent a two-stage assessment procedure which was carried out in a, $40 \pm 2 \mathrm{dBA}$ ambient noise level, $18^{\prime} \times 12^{\prime}$ sound proof room. First, basic audiometric tests with aims to assess hearing and middle ear status were conducted. In order to reach the goals, a Grason-Stadler GSI-61 clinical audiometer plugged with TDH-50P headphones, was used to separately measure air conduction hearing thresholds in both ears. The thresholds, determined by applying modified Hughson-Westlake procedure, were obtained at each octave frequency between $250 \mathrm{~Hz}$ and $8000 \mathrm{~Hz}$. All subjects were fully cooperated and demonstrated good test-retest reliability. Normal hearing was defined as thresholds at $20 \mathrm{~dB}$ HL or better across all frequencies tested.

In order to examine subjects' middle ear status, a standard clinical procedure for acoustic immittance measures was conducted by using a Grason-Stadler GSI Tympstar middle ear analyzer. The procedure consists of tympanometry and acoustic reflexes. Initially, a $226 \mathrm{~Hz}$ probe tone tympanometry was conducted with pump speed at $200 \mathrm{daPa} / \mathrm{sec}$ and air pressure from +200 to $-400 \mathrm{daPa}$. A normal Type A tympanogram was characterized as a sharp amplitude peak centered in between $\pm 50 \mathrm{daPa}$. Subsequently, ipsilateral and contralateral acoustic reflexes with pulsing tone at $500 \mathrm{~Hz}, 1000 \mathrm{~Hz}$ and $2000 \mathrm{~Hz}$ with initial intensity at $75 \mathrm{~dB}$ HL were delivered to determine the reflex thresholds. Reflex thresholds were determined by varying the intensity level in $5-\mathrm{dB}$ increments until the threshold was detected. The thresholds for acoustic reflexes were defined as the lowest level of pulsing tone needed to elicit at least a 0.02 mmhos deflection in middle ear admittance. The presence of Type A tympanogram and normal level of acoustic reflexes ( $\leq 95 \mathrm{~dB} H \mathrm{HL}$ ) defines normal middle ear function.

In the second stage, outer hair cells (OHCs) cochlear function and suppression were tested with an Otodynamics analyzer (Otodynamics, Echoport ILO 288) and ILOV6 software package. The apparatus were used to generate test stimuli and record TEOAE responses. Initially, non-linear click stimulus at $80 \mathrm{dBpe}$ SPL was delivered to determine the functionality of cochlear outer hair cells in both ears. Robust otoacoustic emissions with at least $3 \mathrm{~dB}$ above noise floor suggest healthy outer hair cells cochlear function. The TEOAE recordings were terminated at 260 sweeps and accepted when the TEOAE responses and stimulus stability was at least $60 \%$ and $80 \%$ respectively. Later, the contralateral suppression procedure took place. It involved two consecutive steps; i.e., initially during the absence and later followed by a simultaneously presented $65 \mathrm{~dB}$ HL white noise on the contralateral (non-test) ear. The same audiometer delivered the white noise via $3 \mathrm{~A}$ insert phone to the contralateral ear during OAE measurement on the test ear. In both conditions, absence and presence of noise, $60 \mathrm{dBpe}$ SPL linear clicks were delivered to the test ear. TEOAE was recorded in right and left ear for each subject, where the ear site for test and non-test condition was randomly determined. Two recordings were obtained on each ear for every condition. A one minute break was applied before a second TEOAE measurement was recorded on the same ear. The same steps were then repeated on the non-test ear. The TEO$\mathrm{AE}$ amplitude difference between in quiet and in noise was calculated. The positive difference, between quiet and noise, in the TEOAE amplitudes indicates the presence of TEOAEs suppression. ${ }^{34}$

\section{Statistical analysis}

Analysis was performed using SPSS 21. All data are presented in mean and standard error. In regard to suppression value, the interaction effect between group, gender and ears and main effects were analyzed with a three way mixed ANOVA. The TEOAE amplitude at $80 \mathrm{~dB}$ SPL, separated by diagnosis group, was analyzed using a two way mixed ANOVA. In addition, independent samples t-test was also conducted to compare the mean between ears. 


\section{RESULTS}

\section{Absolute TEOAE amplitude at $80 \mathrm{dBpe}$ SPL}

Table 1, grouped by gender, compares between ears the mean TEOAE amplitudes obtained at $80 \mathrm{dBSPL}$ in normal participants. Data, as suggested by Shapiro-Wilk, were normally distributed ( $p>0.05$ ). A two way mixed ANOVA found no statistically significant interaction between gender and ear $[F(1,21)=0.42, p=0.526]$. Similarly, the main effect of ear and group showed no statistically significant difference between ears $[\mathrm{F}(1,21)=0.40, \mathrm{p}=0.482]$ and between gender $[\mathrm{F}(1,21)=$ $0.022, \mathrm{p}=0.883$ ] respectively. Independent samples t-test, in addition, found no significant difference in mean TEOAE amplitude between ears within each gender group.

The mean TEOAE amplitudes at $80 \mathrm{dBSPL}$ of schizophrenia patients, grouped by gender, were also compared between ears (Table 1). Data were normally distributed (Shapiro-Wilk, $\mathrm{p}>0.05)$. Again, a two way mixed ANOVA indicated no statistically significant interaction between gender and ear $[\mathrm{F}(1$, $21)=0.08, p=0.781]$. Similarly, as in normal group, no statistically significant main effect was noted either between gender $[\mathrm{F}(1$, $14)=0.68, p=0.425]$ or ears $[F(1,14)=0.22, p=0.655]$. Independent samples t-test also revealed no significant difference between ears in each gender group.

The mean TEOAE amplitudes, for right and left ear, were compared between normal and schizophrenia patients. Independent samples t-test showed no significant difference in right ear mean TEOAE amplitude between normal and schizophrenia patients $(\mathrm{p}>0.05)$. Similarly, the difference in left ear TEOAE amplitude between the groups was also not significant $(\mathrm{p}>0.05)$.

\section{Contralateral suppression}

Contralateral suppression was observed in 15 controls and 10 patients with schizophrenia. Three way mixed ANOVA revealed a significant group effect on suppression results $[\mathrm{F}(1$, $41)=6.72, p=0.013]$. In general, patients with schizophrenia showed significantly larger contralateral suppression value compared to healthy controls. Specifically, statistically significantly larger contralateral suppression was observed in the right ear of patients with schizophrenia $[\mathrm{F}(1,23)=4.513, \mathrm{p}=0.045]$ (Figure 1). However, neither ear $[\mathrm{F}(1,41)=2.27, \mathrm{p}=0.139]$, gender $[\mathrm{F}(1$, $41)=1.19, \mathrm{p}=0.282]$ nor interaction effect between group, gender and ear $[\mathrm{F}(1,41)=0.385, \mathrm{p}=0.538]$ showed significant difference (Table 2).

\section{DISCUSSION}

The current study, in general, compares the mean contralateral suppression between patients with schizophrenia and healthy controls. The suppression value obtained from normal subjects in the present study is in agreement with previous studies. ${ }^{39,40}$ The composite, right and left ear, contralateral suppression revealed a statistically significant difference between the two diagnostic groups. Surprisingly, instead of reportedly similar MOC function between healthy controls and schizophrenia patients, ${ }^{29}$ the present study found significantly higher

Table 1. Descriptive and inferential statistical analyses of TEOAE amplitude at $80 \mathrm{~dB}$ SPL in left and right ears of normal and patients with schizophrenia

\begin{tabular}{|c|c|c|c|c|c|c|c|}
\hline \multirow{3}{*}{ Subjects } & \multicolumn{4}{|c|}{ TEOAE amplitude (mean \pm SEM) (dBSPL) } & \multirow{2}{*}{\multicolumn{3}{|c|}{$\mathrm{p}$ value }} \\
\hline & \multicolumn{2}{|c|}{ Male } & \multicolumn{2}{|c|}{ Female } & & & \\
\hline & Left & Right & Left & Right & Group & Ear & Group $\times$ Ear \\
\hline Controls & $14.86 \pm 1.26$ & $15.75 \pm 1.26$ & $15.02 \pm 1.45$ & $15.07 \pm 1.17$ & 0.883 & 0.482 & 0.526 \\
\hline Schizophrenia & $13.53 \pm 0.85$ & $13.03 \pm 0.73$ & $14.05 \pm 0.59$ & $13.93 \pm 0.28$ & 0.425 & 0.655 & 0.781 \\
\hline
\end{tabular}

Statistically significant at $\mathrm{p}<0.05$. TEOAE: transient evoked otoacoustic emissions

Table 2. Statistical analyses of TEOAE suppression level by three-way mixed ANOVA

\begin{tabular}{|c|c|c|c|c|}
\hline \multirow{2}{*}{ Variable } & \multicolumn{4}{|c|}{ TEOAE suppression } \\
\hline & df & Mean square & $\mathrm{F}$ & $\mathrm{p}$ value \\
\hline Group (diagnosis) & 1 & 16.411 & 6.720 & $0.013^{*}$ \\
\hline Gender & 1 & 2.905 & 1.189 & 0.282 \\
\hline Ear & 1 & 5.554 & 2.274 & 0.139 \\
\hline Group $\times$ Gender & 1 & 5.370 & 2.199 & 0.146 \\
\hline Group $\times$ Ear & 1 & 0.769 & 0.315 & 0.578 \\
\hline Gender $\times$ Ear & 1 & 2.095 & 0.858 & 0.360 \\
\hline Group $\times$ Gender $\times$ Ear & 1 & 0.940 & 0.385 & 0.538 \\
\hline
\end{tabular}

*significant difference at $\mathrm{p}<0.05$. TEOAE: transient evoked otoacoustic emissions 


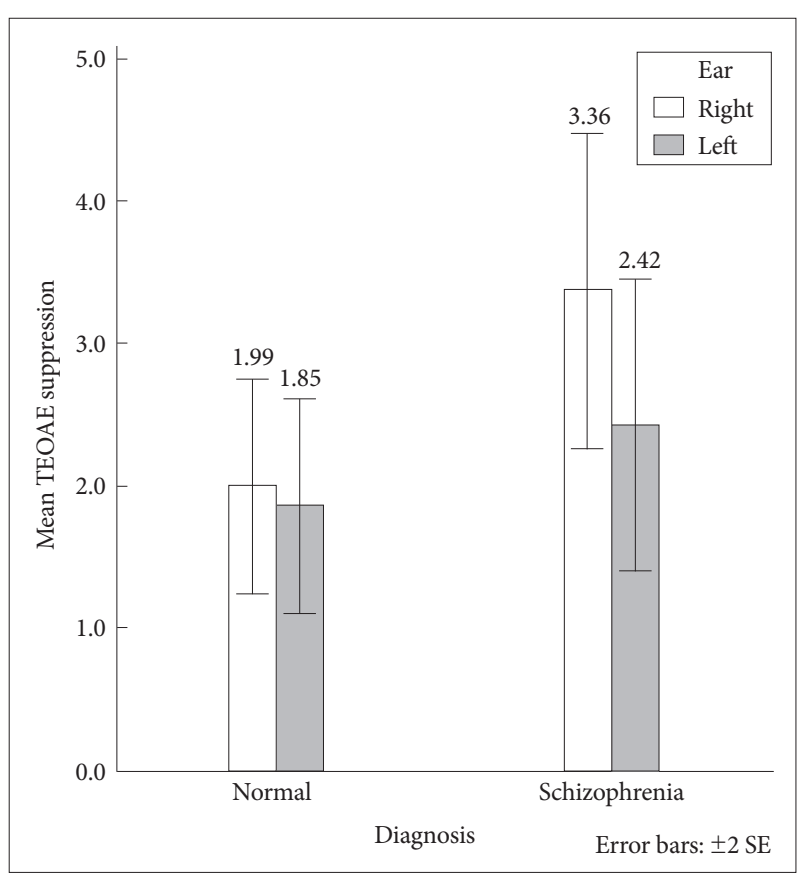

Figure 1. Comparison of mean contralateral suppression between normal and schizophrenia patients for the right and left ear. TEOAE: transient evoked otoacoustic emissions.

suppression value in patients with schizophrenia. The findings could be explained by current understandings on neurotransmitters mechanisms of efferent pathway.

Patients with schizophrenia have been associated with abnormal $\gamma$-aminobutyric acid (GABA) system function. ${ }^{41,42}$ GABA, a neurotransmitter produced in humans' brain, functions to regulate the release of acetylcholine (Ach) at the presynaptic end of efferent auditory neurons. GABA does this by activating its pre-synaptic $\mathrm{GABA}_{B} \mathrm{R}_{\mathrm{s}}$ which inhibits the release of ACh from olivocochlear bundle terminals..$^{43}$ In fact, during the stimulation of the fibers; these two major neurotransmitters have been found at the pre-synaptic neurons. Once released, ACh attaches at $\alpha 9 \alpha 10$ Ach receptors located at the base of OHCs. The activation of these receptors permits the influx of $\mathrm{Ca}^{2+}$ ions into the OHCs. Subsequently, as the concentration of these ions increase in the cells, this leads to opening of SK2 $\mathrm{K}^{+}$channels. Opening of the $\mathrm{Ca}^{2+}$ dependent SK2 $\mathrm{K}^{+}$channels allows the efflux of $\mathrm{K}^{+}$from the OHCs and finally causes hyperpolarization of OHCs. ${ }^{44}$ Hyperpolarization of OHCs subsequently reduces the motility of the cells leading to reduction of OAE amplitude. With regard to the present study, the reduced GABA production in patients with schizophrenia would result in over release of acetylcholine. The over production of Ach in these patients would then lead to hypersensitivity of OHCs micro-mechanisms. Consequently, the hyper-excitation of efferent neurons increases hyperpolarization of OHCs thus leads to larger suppressions.

Since the statistical analysis revealed no significant difference between left and right data in both groups, further considerations should be highlighted. As illustrated in Figure 1, even though the mean TEOAE suppression levels in left and right ears were not statistically different, the value is descriptively higher in the right side among the schizophrenia group. Perhaps by increasing the sample size, more significant outcomes will be obtained. The asymmetry issues among schizophrenia subjects have been investigated. ${ }^{45,46}$ This might approve the contribution of left temporal lobe anomalies as reported in previous studies. For instance, failure in corollary discharge that fails to suppress the activities of left auditory cortex ${ }^{47}$ could lead to stimulation of efferent pathway. In fact, temporal lobe are abnormally active especially during hallucinations. ${ }^{48}$ Thus, we speculate that the abnormal discharge of left temporal lobe would stimulate the neurophysiological function of efferent auditory pathway which, lead to the alteration of OHC mechanisms. In addition, stimulating the left auditory cortex of schizophrenia patients with contralateral acoustic stimulation (CAS) might further enhance the activities of efferent pathway which finally influences $\mathrm{OHC}$ mechanisms. As a matter of fact, inducing efferent MOC with CAS reduces the amplitude of $\mathrm{OAE}^{49}$ which is reflected as increase in suppression value. Nevertheless, the effects of auditory hallucinations on MOC and/or OHC mechanisms require further investigations.

Our current outcomes are in contrast with Veuillet and colleagues findings. ${ }^{29}$ The later, except for differences in laterality, observed no statistically significant difference between healthy controls and schizophrenia groups. They reported that larger suppression in the right ear of healthy controls, as compared to left ear, was not evidenced in the schizophrenia patients. In other words, the pattern of asymmetry in suppression was absence in the latter group. Hence, they speculated that the absence of laterality in schizophrenia patients reflect the lack of right ear advantage (REA). In addition, unlike the healthy controls, the schizophrenia patients showed significantly higher absolute OAE amplitude in the right ear compared to the left ear. They concluded that these could be contributed by more central lateralization anomalies.

The differences in methods applied by Veuillet et al. ${ }^{29}$ and our study could lead to the major discrepancies in outcomes. The former applied 5 levels of linear TEOAE clicks, increased in $3 \mathrm{~dB}$ steps, from 60 to $72 \mathrm{~dB}$ SPL. The contralateral broad band noise, used as CAS, was delivered consistently at $30 \mathrm{~dB}$ SPL. The level was 30 to $42 \mathrm{~dB}$ softer than the presented clicks, which could lead to insufficient suppression effect. In contrast, recent studies on contralateral OAE suppression have consistently applied CAS at least at the same levels of clicks presented to the ipsilateral ear. ${ }^{50,51}$ In our study, CAS was applied at $65 \mathrm{~dB} \mathrm{HL}$, which is still below the acoustic reflex thresholds for normal hearing person. The level is suitable to avoid the contraction of 
stapedial muscle.

The exact reasons why GABA concentration level is reduced in patients with schizophrenia are unclear. Many possible reasons have been discussed including neurodevelopmental and the use of antipsychotic medications. ${ }^{52}$ The level was found higher in schizophrenia patients taking typical compared to atypical antipsychotics. ${ }^{53}$ In another study, which came out with two suggestions, a 6-month intake of atypical antipsychotics by early stage, first episode patients revealed no effect on GABA concentration level. ${ }^{54}$ The study suggested that the treatment either had no effect on GABAergic transmission or it prevented the level from further reduction. As such, the two studies mentioned imply that atypical antipsychotics would probably maintain GABA concentration at low level, hence maintaining the hyperactivity of efferent system. In addition, based on an animal study, the medication was also found to increase the release of cortical $\mathrm{ACh}^{55}$ which may also result in an increase in the suppression value.

Inability to attend towards external speech during an event of auditory hallucinations, a question which was raised to our patients, is one of the phenomenological features limitedly documented in schizophrenia studies. Majority of our patients reported lack of focus towards external sounds which could be simply due to their deficits in attention. Nevertheless, our study suggests an additional factor that might contribute to the feature. The increase in OHCs hyperpolarization during the activation of efferent fibers by the abnormal discharge of auditory cortex would facilitate the condition. The mechanism causes and creates reduction in OHCs motility and "stiffness" in the basilar membrane respectively. As a consequence, in response to external stimuli, lesser electrical signals are transmitted to higher auditory center. Even though this might not be the main contributor, the mechanism however could co-exist during the event of active hallucination. In contrast to the "normal suppression" in healthy controls that helps in enhancing speech perception in background noise, an abnormally larger suppression in schizophrenia could cause insensitive basilar membrane towards incoming signals, particularly speech sounds. Interestingly, as evidenced in our preliminary data on hearing in noise test (HINT), patients with schizophrenia require higher reception thresholds in speech compared to healthy controls during all noise conditions (data not shown). However, further investigations on cochlear mechanisms are required to explain the link between larger suppression and lack of attention towards external speech.

While performing the research, we acknowledged several limitations. Firstly, the present study did not determine the possible influence of gender on TEOAE suppression levels in the tested patients. Since the GABA production is influenced by gender difference, ${ }^{56}$ comparing the TEOAE suppressive effect between male and female patients would provide more information regarding the mechanism of the efferent system. Secondly, only the averaged TEOAE values were analyzed and frequency-specific information was not gathered. If a similar study to be expanded in future, perhaps the TEOAE suppression test could be performed on subjects of different gender and the TEOAE outcomes at specific frequencies should be computed and analyzed.

In conclusion, the larger contralateral suppression found in patients with schizophrenia suggests the hyperactivity and neurophysiological deficits of their efferent auditory pathway. The larger right ear suppression in the patients group might support abnormal discharge of their left auditory cortex.

\section{REFERENCES}

1. Bhugra D. The global prevalence of schizophrenia. PLoS Med 2005;2: e151.

2. Keshavan MS, Nasrallah HA, Tandon R. Schizophrenia, "Just the Facts" 6. Moving ahead with the schizophrenia concept: From the elephant to the mouse. Schizophr Res 2011;127:3-13.

3. Keshavan MS, Tandon R, Boutros NN, Nasrallah HA. Schizophrenia, "just the facts": what we know in 2008 Part 3: neurobiology. Schizophr Res 2008;106:89-107.

4. van Haren NE, Cahn W, Hulshoff Pol HE, Kahn RS. Schizophrenia as a progressive brain disease. Eur Psychiatry 2008;23:245-254.

5. Rish I, Cecchi G, Thyreau B, Thirion B, Plaze M, Paillere-Martinot ML, et al. Schizophrenia as a network disease: disruption of emergent brain function in patients with auditory hallucinations. PLoS One 2013;8: e50625.

6. Wu KY, Chao CW, Hung CI, Chen WH, Chen YT, Liang SF. Functional abnormalities in the cortical processing of sound complexity and musical consonance in schizophrenia: evidence from an evoked potential study. BMC Psychiatry 2013;13:158.

7. Näätänen R, Kähkönen S. Central auditory dysfunction in schizophrenia as revealed by the mismatch negativity (MMN) and its magnetic equivalent MMNm: a review. Int J Neuropsychopharmacol 2009;12:125-135.

8. Iliadou VV, Apalla K, Kaprinis S, Nimatoudis I, Kaprinis G, Iacovides A. Is central auditory processing disorder present in psychosis? Am J Audiol 2013;22:201-208.

9. Musiek F, Ballingham TM, Liu B, Paulovicks J, Swainson B, Tyler K, et al. Auditory hallucinations: an audiological perspective. Hear J 2007;60: 32-52.

10. Rihs TA, Tomescu MI, Britz J, Rochas V, Custo A, Schneider M, et al. Altered auditory processing in frontal and left temporal cortex in 22q11.2 deletion syndrome: a group at high genetic risk for schizophrenia. Psychiatry Res 2013;212:141-149.

11. Curcic-Blake B, Liemburg E, Vercammen A, Swart M, Knegtering H, Bruggeman $\mathrm{R}$, et al. When Broca goes uninformed: reduced information flow to Broca's area in schizophrenia patients with auditory hallucinations. Schizophr Bull 2013;39:1087-1095.

12. Hoffman RE, Pittman B, Constable RT, Bhagwagar Z, Hampson M. Time course of regional brain activity accompanying auditory verbal hallucinations in schizophrenia. Br J Psychiatry 2011;198:277-283.

13. Simons CJ, Tracy DK, Sanghera KK, O’Daly O, Gilleen J, Dominguez $\mathrm{MD}$, et al. Functional magnetic resonance imaging of inner speech in schizophrenia. Biol Psychiatry 2010;67:232-237.

14. Kwon JS, McCarley RW, Hirayasu Y, Anderson JE, Fischer IA, Kikinis R, et al. Left planum temporale volume reduction in schizophrenia. Arch Gen Psychiatry 1999;56:142-148.

15. Modinos G, Costafreda SG, van Tol MJ, McGuire PK, Aleman A, Al- 
len P. Neuroanatomy of auditory verbal hallucinations in schizophrenia: a quantitative meta-analysis of voxel-based morphometry studies. Cortex 2013;49:1046-1055.

16. O'Daly OG, Frangou S, Chitnis X, Shergill SS. Brain structural changes in schizophrenia patients with persistent hallucinations. Psychiatry Res 2007;156:15-21.

17. Hugdahl K, Løberg EM, Nygård M. Left temporal lobe structural and functional abnormality underlying auditory hallucinations in schizophrenia. Front Neurosci 2009;3:34-45.

18. Hugdahl K, Loberg EM, Jorgensen HA, Lundervold A, Lund A, Green MF, et al. Left hemisphere lateralisation of auditory hallucinations in schizophrenia: a dichotic listening study. Cogn Neuropsychiatry 2008; 13:166-179.

19. Källstrand J, Nehlstedt SF, Sköld ML, Nielzén S. Lateral asymmetry and reduced forward masking effect in early brainstem auditory evoked responses in schizophrenia. Psychiatry Res 2012;196:188-193.

20. Nam EC. Is it necessary to differentiate tinnitus from auditory hallucination in schizophrenic patients? J Laryngol Otol 2005;119:352-355.

21. Igata M, Ohta M, Hayashida Y, Abe K. Missing peaks in auditory brainstem responses and negative symptoms in schizophrenia. Jpn J Psychiatry Neurol 1994;48:571-578.

22. Leavitt VM, Molholm S, Ritter W, Shpaner M, Foxe JJ. Auditory processing in schizophrenia during the middle latency period (10-50 ms): highdensity electrical mapping and source analysis reveal subcortical antecedents to early cortical deficits. J Psychiatry Neurosci 2007;32:339-353.

23. Pickles JO. The Centrifugal Pathways. In: Pickles JO, Editor. An introduction to the physiology of hearing. 2nd Ed. London: Academic Press; 1988, p. 235-255.

24. Perrot X, Ryvlin P, Isnard J, Guénot M, Catenoix H, Fischer C, et al. Evidence for corticofugal modulation of peripheral auditory activity in humans. Cereb Cortex 2006;16:941-948.

25. Aleman A, Bocker KB, Hijman R, de Haan EH, Kahn RS. Cognitive basis of hallucinations in schizophrenia: role of top-down information processing. Schizophr Res 2003;64:175-185.

26. Mishra SK, Lutman ME. Top-down influences of the medial olivocochlear efferent system in speech perception in noise. PLoS One 2014;9: e85756.

27. Suga N. Tuning shifts of the auditory system by corticocortical and corticofugal projections and conditioning. Neurosci Biobehav Rev 2012;36: 969-988.

28. Leon A, Elgueda D, Silva MA, Hamame CM, Delano PH. Auditory cortex basal activity modulates cochlear responses in chinchillas. PLoS One 2012; $7: e 36203$.

29. Veuillet E, Georgieff N, Philibert B, Dalery J, Marie-Cardine M, Collet L. Abnormal peripheral auditory asymmetry in schizophrenia. J Neurol Neurosurg Psychiatry 2001;70:88-94.

30. De Ceulaer G, Yperman M, Daemers K, Van Driessche K, Somers T, Offeciers FE, et al. Contralateral suppression of transient evoked otoacoustic emissions: normative data for a clinical test set-up. Otol Neurotol 2001;22:350-355

31. Yalçınkaya F, Yilmaz ST, Muluk NB. Transient evoked otoacoustic emissions and contralateral suppressions in children with auditory listening problems. Auris Nasus Larynx 2010;37:47-54.

32. Giraud AL, Collet L, Chéry-Croze S, Magnan J, Chays A. Evidence of a medial olivocochlear involvement in contralateral suppression of otoacoustic emissions in humans. Brain Res 1995;705:15-23.

33. Stuart A, Butler AK. Contralateral suppression of transient otoacoustic emissions and sentence recognition in noise in young adults. J Am Acad Audiol 2012;23:686-696.

34. Ugur AK, Kemaloglu YK, Ugur MB, Gunduz B, Saridogan C, Yesilkaya $\mathrm{E}$, et al. Otoacoustic emissions and effects of contralateral white noise stimulation on transient evoked otoacoustic emissions in diabetic children. Int J Pediatr Otorhinolaryngol 2009;73:555-559.

35. Giraud AL, Collet L, Chéry-Croze S. Suppression of otoacoustic emission is unchanged after several minutes of contralateral acoustic stimula- tion. Hear Res 1997;109:78-82.

36. Prasher D, Ryan S, Luxon L. Contralateral suppression of transiently evoked otoacoustic emissions and neuro-otology. Br J Audiol 1994;28: 247-254.

37. Leucht S, Kane JM, Kissling W, Hamann J, Etschel E, Engel R. Clinical implications of Brief Psyciatric Rating Scales scores. Br J Psychiatry 2005; 187:366-371.

38. Wahab S, Zakaria MN, Sidek D, Abdul Rahman AH, Shah SA, Abdul Wahab NA. Evaluation of auditory hallucinations in patients with schizophrenia: a validation study of the Malay version of Psychotic Symptom Rating Scales (PSYRATS). Psychiatry Res 2015;228:462-467.

39. Urnau D, Tochetto TM. Occurrence and suppression effect of otoacoustic emissions in normal hearing adults with tinnitus and hyperacusis. Braz J Otorhinolaryngol 2012;8:87-94.

40. Abdollahi FZ, Lotfi Y. Gender difference in TEOAEs and contralateral suppression of TEOAEs in normal hearing adults. Iran Rehab J 2011;9: 22-25.

41. Daskalakis ZJ, George TP. Clozapine, GABA(B), and the treatment of resistant schizophrenia. Clin Pharmacol Ther 2009;86:442-446.

42. Farzan F, Barr MS, Levinson AJ, Chen R, Wong W, Fitzgerald PB, et al. Evidence for gamma inhibition deficits in the dorsolateral prefrontal cortex of patients with schizophrenia. Brain 2010;133(Pt 5):1505-1514.

43. Wedemeyer C, Zorrilla de San Martín J, Ballestero J, Gómez-Casati ME, Torbidoni AV, Fuchs PA, et al. Activation of presynaptic GABA(B $(1 \mathrm{a}, 2))$ receptors inhibits synaptic transmission at mammalian inhibitory cholinergic olivocochlear-hair cell synapses. J Neurosci 2013;33: 15477-15487.

44. Im GJ. Role of nicotinic acetylcholine receptor on efferent inhibition in cochlear hair cell. Korean J Audiol 2012;16:108-113.

45. Källstrand J, Nehlstedt SF, Sköld ML, Nielzén S. Lateral asymmetry and reduced forward masking effect in early brainstem auditory evoked responses in schizophrenia. Psychiatry Res 2012;196:188-193.

46. Collinson SL, Mackay CE, O J, James AC, Crow TJ. Dichotic listening impairments in early onset schizophrenia are associated with reduced left temporal lobe volume. Schizophr Res 2009;112:24-31.

47. Ford JM, Mathalon DH. Corollary discharge dysfunction in schizophrenia: can it explain auditory hallucinations? Int J Psychophysiol 2005; 58:179-189.

48. Shergill SS, Brammer MJ, Williams SC, Murray RM, McGuire PK. Mapping auditory hallucinations in schizophrenia using functional magnetic resonance imaging. Arch Gen Psychiatry 2000;57:1033-1038.

49. Guinan JJ. Olivocochlear efferents: anatomy, physiology, function, and the measurement of efferent effects in humans. Ear Hear 2006;27:589-607.

50. Geven LI, de Kleine E, Free RH, van Dijk P. Contralateral suppression of otoacoustic emissions in tinnitus patients. Otol Neurotol 2011;32:315-321.

51. Stuart A, Preast JL. Contralateral suppression of transient-evoked otoacoustic emissions in children with sickle cell disease. Ear Hear 2012;33: 421-429.

52. O'Connor WT, O'Shea SD. Clozapine and GABA transmission in schizophrenia disease models: establishing principles to guide treatments. Pharmacol Ther 2015;150:47-80.

53. Tayoshi S, Nakataki M, Sumitani S, Taniguchi K, Shibuya-Tayoshi S, Numata $S$, et al. GABA concentration in schizophrenia patients and the effects of antipsychotic medication: a proton magnetic resonance spectroscopy study. Schizophr Res 2010;117:83-91.

54. Goto N, Yoshimura R, Kakeda S, Moriya J, Hori H, Hayashi K, et al. No alterations of brain GABA after 6 months of treatment with atypical antipsychotic drugs in early-stage first-episode schizophrenia. Prog Neuropsychopharmacol Biol Psychiatry 2010;34:1480-1483.

55. Ichikawa J, Dai J, O’Laughlin IA, Fowler WL, Meltzer HY. Atypical, but not typical, antipsychotic drugs increase cortical acetylcholine release without an effect in the nucleus accumbens or striatum. Neuropsychopharmacology 2002;26:325-339.

56. Mandal A, Mishra S, Mandal P. Sex specific differences in GABA and glutamate levels in response to cigarette smoke. Sci Rep 2013;2:613-614. 